China Perspectives

$2010 / 1 \mid 2010$

Independent Chinese Cinema: Filming in the "Space of the People"

\title{
Building a Public Consciousness
}

A Conversation with Jia Zhangke

\section{Sebastian Veg}

\section{OpenEdition \\ Journals}

\section{Electronic version}

URL: http://journals.openedition.org/chinaperspectives/5060

DOI: 10.4000/chinaperspectives.5060

ISSN: 1996-4617

\section{Publisher}

Centre d'étude français sur la Chine contemporaine

\section{Printed version}

Date of publication: 21 April 2010

ISSN: 2070-3449

\section{Electronic reference}

Sebastian Veg, «Building a Public Consciousness », China Perspectives [Online], 2010/1 | 2010, Online since 01 April 2013, connection on 28 October 2019. URL : http://journals.openedition.org/ chinaperspectives/5060 ; DOI : 10.4000/chinaperspectives.5060 
(1)

\title{
Building a Public
}

\section{Consciousness}

\author{
A Conversation with sia Zhangke
}

This text is transcribed from the recording of a panel discussion organised on 13 April 2009 by the Hong Kong International Film Festival and the French Centre for Research on Contemporary China, as part of the symposium "Between public and private : A space for independent Chinese cinema." Jia Zhangke's answers to two additional audience questions have been inserted into the discussion where they seemed most relevant.

Sebastian Veg (SV): Could you talk a little about how independent Chinese film relates to private and public space? At the beginning, independent film seemed like a very private activity, something that a few friends would do together. But, as time went by, it occupied a more and more important position within society, and thus also entered the public domain, touching on many social questions that other activities don't address, such as discussion on the "lower classes" (diceng).

Jia Zhangke (JZK): To answer this question, I should go back to the cultural situation in China in the past. After 1949, the leading role was played by so-called revolutionary culture. Individual art was marginalised or even disappeared; for example, only in the 1980s did younger people like us discover Shen Congwen, Eileen Chang, or Fei Mu's films. Revolutionary culture became a model, which from the point of narrative was a literary model based on its popular quality (tongsu) and on legend (chuanqi). It was popular in that it had to reach all strata of society, even people with almost no education. This was a very important part of revolutionary culture. The other aspect is legend: this includes the heroic qualities of revolutionary narratives, like The White-Haired Girl (Bai mao nü). Film was strongly influenced by these two principles: it had to transmit a mainstream discourse.

When we began making films, we had almost forgotten that film could actually transmit our own individual feelings. The best example of this is scar literature and film. After the catastrophe ended, the people who had experienced such a period of tremendous turmoil wrote a type of literature that took a completely mainstream position, reflecting the Party's own change in attitude. This was a great pity. A lot of things had been obscured in the revolutionary narratives: private space, daily space. The only thing that was preserved was memories of the collective. The only slightly less ideological activities were things like playing basketball,

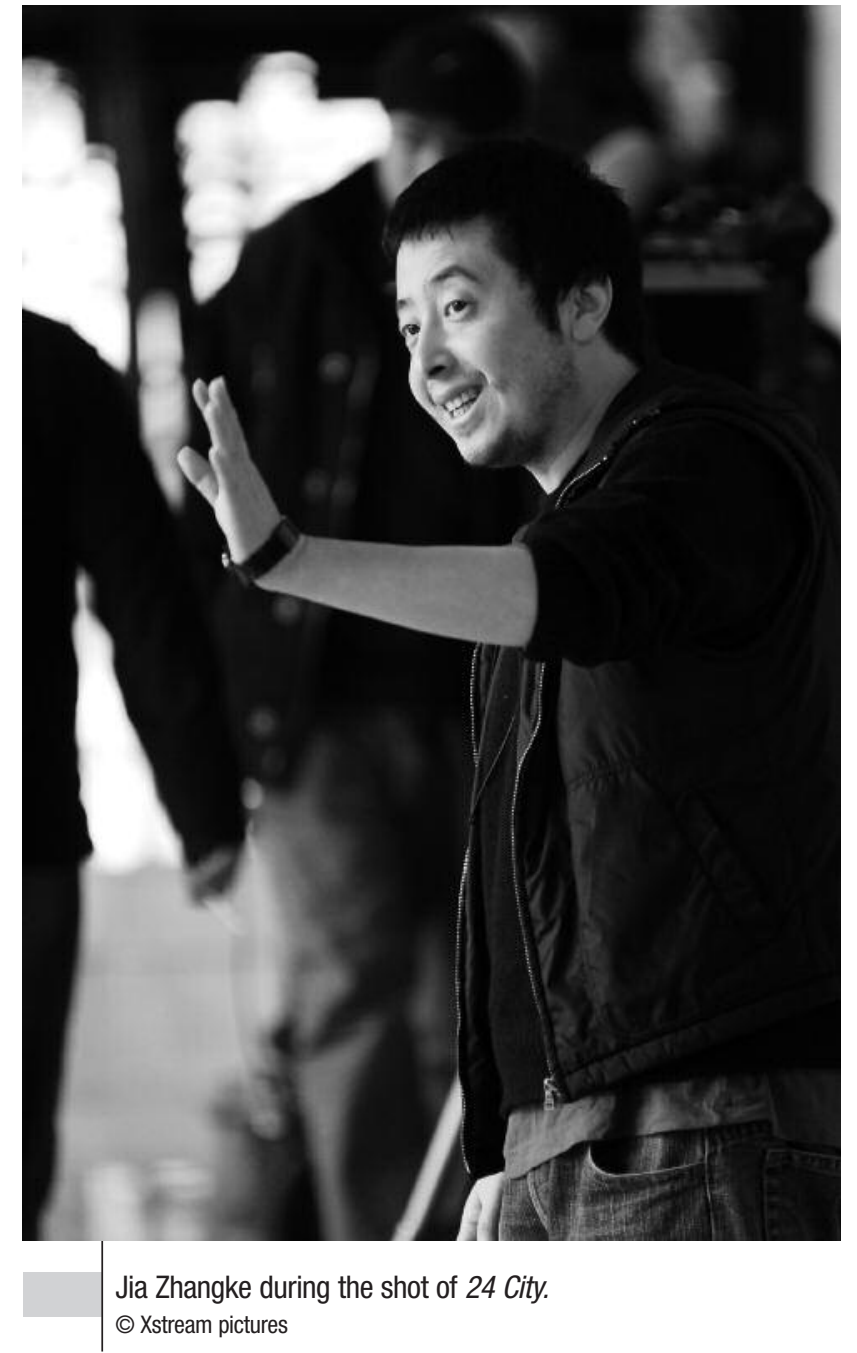

sports, etc. But there was almost no mention of private space, such as a couple's life at home. This revolutionary culture reflected a social structure based entirely on the collective, on the work unit (danwei).

Therefore, after the opening up and reform in the 1980s, cultural fever spread throughout China. Even in my remote 
hometown, we could suddenly read Nietzsche's works. This brought about a new attention to the self; it opened our eyes to the individuals' rights, their sub-consciousness, psychology, weaknesses. In the 1980s, this wave of philosophical readings, of cultural change, brought about an awakening to the idea that the individual could be the subject of a work of art: we could express our ideas and in particular our weaknesses. Not as a narrative, but as a substitute for the mainstream discourse: everything was available, everything was possible.

Consequently, when in the 1990s independent Chinese cinema appeared with Zhang Yuan and Wang Xiaoshuai, I saw their work as being really a return to private and everyday life: you could suddenly see ordinary Chinese people on the screen, people who had their worries, who had experienced changes, not the boundless exaggerated happiness of the films we had watched earlier. On the one hand, it meant the return of authors, as real individuals, to cinema; on the other, ordinary, private life, individual space, began to appear on the screen, for example in The Days (Dongchun de rizi): a couple with a small apartment in Beijing, their hometown, their personal memories, an old train station, an old railway employee... I think the return to private space was underpinned by this sort of cultural adjustment, this sort of change. Another point is the problem of the space for the dissemination (chuanbo) of films. As a director, I'm wary of two kinds of pressure. I experienced the first one before 2003: from Zhang Yuan's Mama until 2003, when China decided to marketise the film industry, the main pressure was ideological, the pressure of censorship. Independent film at this time was mainly underground film. Because circulation of these films was entirely private, because it was entirely prevented in the public space, you exchanged video tapes, which were limited even in bars and universities. After 2003, when the Chinese government decided that film was also an industry, consumerism came to the mainland, and the pressure become double. On the one hand, the pressure of censorship and control still existed. Although there was some opening and traces of progress, the method remained the same. On top of that we now had the pressure of the market. Now, the problem faced by these independent films became their rejection by the market. Power now has a new face: it is disguised as what is "not acceptable to the market." For this reason, independent film has now become a museum culture; as soon as you finish shooting, you enter the museum system. In my view film should be part of a nor$\mathrm{mal}$ commercial system. Making independent films does not mean refusing the market. In this sense, it's a great pity that the most normal bridge between a film and its audience, i.e., the commercial distribution system, has not been adequately opened for independent film, and that a more public space for independent film has not been opened.

SV: These private stories you mentioned: what kind of position do you think they should occupy in society? When you tell the stories of private people, what sort of position does the director have with respect to the object $\mathrm{s} / \mathrm{he}$ is filming? You have sometimes talked about the ethical position of the film director. How is it defined?

JZK: The individual point of view is what is most important. When I finish a film, I know that my relation to what I am filming is that I am recording changes, for example the changes of the late 1970s, or the material improvements experienced by Chinese society. I still have very vivid memories of hunger from before the end of the Cultural Revolution, when I was five or six (I was born in 1970), at a time when the material situation was still very difficult. I also have memories of violence: I remember the meetings, meetings of 10,000 people, called struggle sessions (pidouhui). Although I don't remember why people were beaten or had violence inflicted on them, I have these memories of terror. Then, after the end of the 1970s, very quickly we had the household-responsibility system, village reform, and there was no more hunger, material conditions improved. We started to have television sets, washing machines, and therefore also moved from revolutionary culture to popular culture: television series, Hong Kong series like The Bund ${ }^{(1)}$ and $H_{u o} Y_{u a n j i a .}{ }^{(2)}$ From this pop culture, we learned about new social groups, like the triads. Previously, we would only sing revolutionary songs. As children, we would usually all begin by learning "We are the heirs of socialism" (Women shi shehui zhuyi jieban ren), all these songs that were always in the plural, that were collective. But then, Teresa Teng sang in the singular: "The Moon stands for my heart" (Yueliang daibiao wode xin); she was singing about the individual, the self.

I have all these innumerable memories of change - concrete, not conceptual memories. But now in this time of accelerated transformation, speaking of them from a public perspec-

1. This series, made by Hong Kong TVB in 1980 (Shanghai tan), starring Chow Yun-fat and Ray Lui as triad members in 1920s Shanghai, was a huge success and was remade several times in series and feature films. (All footnotes by the translator)

2. Huo Yuanjia (1868-1910; Fok Yuen Gap in Cantonese), a martial arts practitioner from Tianjin, became the subject of a Hong Kong ATV series in 1981 called The Legendary Fok, also remade several times, most recently in the film Fearless starring Jet Li in 2006. 
tive seems to deprive them of detail. Speaking on a general level of political or economic change leaves us with only concepts. For example, speaking of the Three Gorges from a macro-economic or political perspective, you say that 1 million people were displaced, dozens of cities with several centuries of history were submerged. But these are ideas, they cannot be experienced. From the perspective of film, the perspective of individual experience, we can provide countless details that make change something that can be felt. I think individual experience does not necessarily mean it is unique; it is always also universal. From this angle, I like Wang Xiaobo's discussion with $\mathrm{Hsu}$ Cho-yun about how art should construct a fruitful relationship between the individual and society. ${ }^{(3)} \mathrm{How}$ is individual experience part of collective memory? Individual experience gives a changing society - or even if it is not changing - details that can be felt. These details cannot appear in any other area but the area of art. So from this point of view, individual experience is a common experience.

Then there is another aspect, which is what sort of use this kind of individual, independent experience can be put to. Ever since 2003, when I was given the opportunity to officially distribute my films in China, from The World to Still Life and 24 City, I've been asked time and time again by the media: "Jia Zhangke, why do you always want to film the lower strata of society (diceng)? These people don't watch your films!" This seems to be a very ingenious question, a very acute paradox in my work, but for me there is no paradox at all, because the usefulness of film, as a form of cultural production, cannot be assessed in numbers. These days books in mainland China are considered bestsellers at 12,000 copies, while films are seen by hundreds of millions. I remember going to see Kung Fu Hustle in Shenzhen, I could only get tickets for two in the morning, and the rest of the theatre was full of cooks still wearing their white hats books simply can't compare. But culture cannot be assessed on a one-on-one basis. A film is not only useful when it's seen by 100 million people, because it enters into a form of public consciousness (gonggong yishi). When the problems you are alerted to while carrying out this sort of investigation become part of the public consciousness, this development is useful for the entire culture. These last few years, not only film or art but also journalism, sociology, all these forms of culture have had an impact on changing society. For example, people today no longer dare to say: we can simply overlook ordinary people. This is how public consciousness is formed. And this is the function of culture. In the 1990s, when we first discussed the material of 24 City, at the time of the greatest layoffs for the Chinese work- ers, there was a sort of philosophy of the strong: we must change, we must move from a planned economy to a market economy. Everyone agreed that the planned economy was not reasonable, and that we needed to move to a free economy, that's fine. The problem was with the philosophy of the strong: the idea that to make this change we needed to sacrifice so many people. That is simply wrong, in my opinion. It was an instrumental political theory. If there needed to be sacrifices, why did it have to be those people? So at that time, there was still a sort of cultural problem; but I'm confident that today, no matter what policy changes or adjustments are made, we already have this public consciousness. This sort of awareness has entered people's hearts. So in this sense, the process from individual experience and personal demands to the process of dissemination and its limits is not something I believe we need to worry about, because you never know what sort of use things may be put to. Myself, I became interested in film because I liked Yellow Earth, but very few people had seen it. Even up to now, it is still a defining cultural experience of the 1980s; it deeply influenced the society of the times, and in this sense it is also an example of the importance of culture.

\section{SV: You mentioned Wang Xiaobo. Do you think that inde- pendent film can influence what Wang Xiaobo described as the "silent majority"? Do you think that its half-private half- public nature can set off a process that allows public opinion to materialise?}

JZK: I don't really believe that the silent majority is apathetic. If you are really in contact with people, you can actually see that they have, in various ways, preserved a habit of reading, of seeing films, of reflecting. For example, we just discussed the problem of distribution. There is definitely a problem with the commercial circuit: places like my hometown, which is a county town with quite a large population, no longer have a single cinema. In the 1980s, we had one called the Sanjia theatre, which no longer exists. Of the three screens in it, one became supermarket, one is a place to speculate on the stock market, another is a furniture store: it has changed into three different spaces. But films can be distributed in other venues, like on the Internet. I discovered that even in very remote areas of Shanxi, in mining villages,

3. Hsu Cho-yun [Xu Zhuoyun], Honorary Fellow of the Academia Sinica and a professor of history at Pittsburgh University for over 30 years, became the writer Wang Xiaobo's mentor when he studied in Pittsburgh in the 1980s. In his essays published under the title of The Silent Majority and My Spiritual Garden, Wang Xiaobo frequently mentions his discussions with "my teacher" (wo de laoshi) 
Filming the factory in 24 City: "Public spaces always have a form of power behind them; they're always related to the structures of society." (C) Xstream pictures

there is always an Internet café where you can surf the web and download films. In this sense the distribution system is still in the midst of transformation, in the middle of the road. You cannot rule out the possibility of more opportunities for films to be circulated, to reach more people.

[...] However, I remain relatively optimistic about the nature of the commercial system. Because at present, the main problem is still censorship: when importing films, you still have to go through the two government monopoly firms, Zhong Ying and Huaxia. I believe that if you rely only on local production, you cannot work in a sustainable manner 365 days a year. For example in France, a company like MK2 doesn't sell only French films, but may also distribute Iranian, Kazakh, or South African films. And France has many small distributors who work in this manner. Therefore I know that if I go to MK2, I will always find a film that suits my taste. You can't do that in China. So as long as there is this form of censorship, even a commercial system cannot be viable. And there are many problems. In China, students or young people don't go to the cinema; they all download films from the Internet. How can you regulate this? For example, when Still Life was distributed officially in China, it was watched by about 1 million people in theatres, but it was seen by many more people, on DVDs, through all sorts of channels. Previously, pirated DVDs were the biggest menace to films, but now even pirated DVDs are done for, because their price of 5 yuan has become too expensive. And the Internet is not the best channel for obtaining a return on investment.

SV: In your films, although you often tell private stories, you often film in public spaces, such as railway or bus stations, or in the case of 24 City, a factory. What is the relationship between the individual and these spaces? How do these spaces relate to the system?

JZK: Public spaces always have a form of power behind them; they're always related to the structures of society. So the people that move across these spaces always have a more orderly, a more systematic relationship with the system. For example, if you take a train, it's not only a train, an opportunity for travel, but also an extremely powerful space: for example if you are not able to but a ticket, and you board the train and need to look for the conductor to obtain a seat, then you are really in a direct relationship with power. It's not at all like being in contact with a transportation company - it is, after all, the railroad ministry! So you will see all the negative aspects of power. When people pass through public spaces, by observing their appearance, their demeanour,

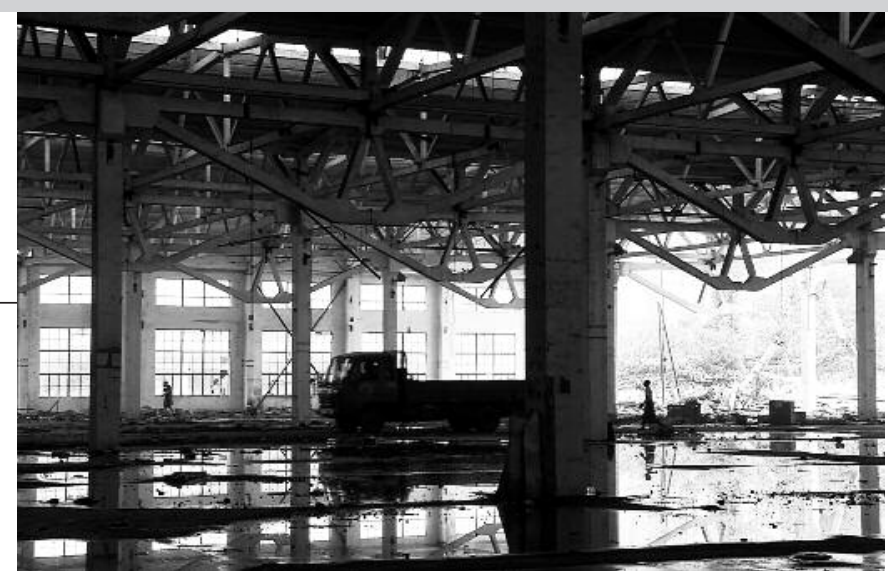

you will get a very good idea of the relationship between an individual and the entire public system. For example, when we were shooting In Public, we shot the Datong train station. There was someone there fast asleep, apparently exhausted. But I noticed a detail: although he was sleeping, he was still tightly grasping his bag with two hands, holding on to the zipper. By looking at his hands you could observe the dangers of travel, the chaos in society, the stealing right and left. So from an individual gesture, an individual reaction, you can understand the phenomenon of power.

SV: Whether filming as an amateur or as a professional, do you think that your work has any relation to what was traditionally - or even more recently - called "taking responsibility for all under heaven"? Is there a feeling that, for example when filming the "lower strata," because the authorities will not take responsibility, you must turn your camera on them? Or do you simply see film as a kind of private hobby, shooting whatever you like, without having to give any justification for it?

JZK: I have never felt that I had any kind of responsibility to shoot any kind of film. I also don't think I can represent these people. Actually, this is also a very personal situation: I myself grew up in this environment. I was the child of the most ordinary kind of Chinese family in the most ordinary kind of Chinese county town. But in this ordinary town I experienced so many things that they gave me a justification: I became someone who wanted to express himself, I wanted to express what I had experienced. For example, in high school, I wanted to express myself, but didn't know how to - so I went break-dancing, and expressed it with my body. And then I wrote poetry. I think in every era, young people in China have chosen a particular way of expressing themselves, and in the 1980s it was poetry, so we studied the works of Bei Dao and Gu Cheng. Then poetry was not enough, so I turned to writing stories, and then to film, which I discovered I liked most. This was a long process of looking for an individual way out, because the experience can be very painful, very perplexing, but you want to talk about it, so you look for a method, an environment. When you can't play the piano or engage in any of the more elegant forms of expression, taking a pen to write is the simplest. When I saw Yellow Earth, I thought: "This is wonderful." Because it sur- 
passed language. I had tried writing, but you need to be good with words, whereas with film you don't need words to understand the language. So my attraction to film, to being a director, did not stem from any feeling of responsibility, but developed as an answer to the problem of personal expression. I felt I couldn't express myself - of course some people don't care, that's a question of temperament, maybe it's more romantic people who become directors.

On the other hand, I think it's true that when you choose an occupation, you necessarily have a social ideal, so in addition to expressing myself, I also had this kind of aspiration. When I studied at the Beijing Film Academy, I watched official Chinese films for many years and never saw anything related to my life. So I did feel I had to film our lives, but I don't like to describe it as a responsibility, or a mission. When people talk about a mission, it's usually to assert their own power, their discursive power, which is something I reject.

To touch on the question of acting: using non-professional actors was a form of revolt against the film world I had experienced, in which actors were never natural, everything was rehearsed. They spoke Mandarin, and a form of Mandarin that was specifically achieved through actor's training, like television presenters. So why did I use amateur actors like Wang Hongwei? Because his body is always slouching, just like all of us in life are always slouching, no one stands straight like an actor all the time. Non-professional actors can speak dialect. Mandarin is a very violent thing. Each dialect is some people's mother tongue. Why should people be restricted from using their mother tongue in film and be forced to speak a language they've had to acquire? When they act in dialect, it has an incredible seductiveness, a radiance; the purity of the vocabulary in any dialect is incomparable to anything in Mandarin. For example, if you say, Wo ai ni (I love you), this is very embarrassing; you never say something like that. But in Hong Kong films, when people say Ngo jongyi nei (wo zhongyi ni), it's much less direct, not as abrupt as ai; "al" just goes too far, being measured is much better. This is also a form of our private experience, a way of releasing our own charm. The situation is better now, but I remember at the time I shot Xiao $W u$, the Film Bureau censorship rules had a provision stipulating that in order to promote Mandarin we should not film in dialect. If we had to use dialect, we had to write a report. At the end, only Mao Zedong was allowed to speak dialect. And Zhou Enlai. Nobody else could speak their mother tongue. This was another form of autocracy.
Esther Cheung: Let me use my Cantonese dialect to ask a question about expression. Many of your films started out with a documentary and then developed into a feature. I'm interested in this process. How does an artist find a viewpoint in the material of life: in what kind of situation, through what kind of feeling do you reach this sort of vantage point, and how do you realise that you have the material for a film? For example, how did you evolve from Dong to Still Life?

JZK: Personally I very much enjoy making feature films, yet I also very much hope to preserve my habit of making documentaries. The first time I made such a link between feature and documentary was in 2001, when I shot In Public using digital video for the first time. I shot the documentary for one month in the spring: it was mainly about spaces, so I shot many spaces: the train station, bus station, restaurant, ballroom, and the saunas that were just appearing at that time. In these saunas there were men who would not go home at night, so I wanted to interview them and find out why they wouldn't go home. In the course of shooting, $\mathrm{Da}$ tong's public spaces made a very strong impression on me, especially their contrasts, and there were some very strong ones.

In that year, China's development accelerated drastically: the bid to organise the Olympics had succeeded, China had entered WTO. For places with a strong traditional industry like Datong - which is a coal city - this transformation, especially the closure of the coal mines, brought about a strong feeling of desolation. And in the media, we would see press conferences for all sorts of new brand-name shops or cars: Louis Vuitton, BMW, there seemed to be a new one every day. So in this kind of situation, because I had made the documentary, I really wanted to make a feature about this city, about how its resources had dried up. So Unknown Pleasures was a film that grew out of a city: it was because of this space, because of the desolate buildings in the mining districts, that I began investigating those young people, and decided to make the film. Since then, I've always had two types of inspiration: one comes from people, or types of people, and the other comes from spaces.

Ever since The World, I have been looking for a kind of public space, of public time that can interact with the shooting of the film. For example, the park depicted in The World really exists: there is one in Beijing and one in Shenzhen. The park itself contains a lot of information about our modern world and culture, so it's very conducive to setting a story in it. If you go to the Three Gorges, there really is a 
Four fictional characters are mixed in among the real interview in 24 City. From top to bottom: Hao Dali (played by Lü Liping), Song Weidong (Chen Jianbin), Xiao Hua (Joan Chen), Su Na (Zhao Tao).

(C) Xstream pictures

huge dam, as well as those displaced people and towns. So I set a film within this public space, this public event. In 24 City, there is a real factory, Factory 420 , which becomes a development called 24 City. So I hope to establish a significant relationship between reality and film, between fiction and truth, so that in 10 or 20 years, when you see these films, you can see this sort of interaction, and the documentality (wenxianxing) of these films, the fact that they are not entirely fictitious, but provide something more that can be investigated, something symbolic. Perhaps this concern stems from my being worried about forgetting, because we really are a very forgetful people; certain aspects of reality are here today and gone tomorrow. And perhaps, on a psychological level, mixing documentary aspects with fiction makes me feel that my films belong to real life experience, that they are indestructible evidence.

[...] I think feature film and fiction are also bridges to reality. For example the fictional part of 24 City was made by condensing a lot of documentary material. Kieslowksi once said that when making a documentary, the closer you stick to reality, the more absurd and unreal the film becomes. Sometimes if you try to document certain things, the result will be the opposite of what you expect, because here is not only material reality, but also the reality of experience, including psychology and subjectivity. This is why we need fiction to attain an aesthetic form of reality. A film cannot attain documentality through fiction alone; the question is the relation between fiction and documentary. In 24 City there are interviews with five real workers and four fictional characters. The latter effectively express certain things that could not be expressed in the documentary interviews. Each of the real interviews was like a case, and these cases compose a kind of evidence, so together I think they have a documental nature. On the other hand, when you are trying to establish a relationship between the public space and the public time of reality, as in the World Park depicted in The World, this actually entails a very complex cultural form. World Park seems very open on the surface, but it's actually very closed: the cultural forms associated with every place in the world, although confined to the background, still provide a sort of pier to fiction; if fiction is a boat, this type of reality is a sort of pier. It interacts very boldly with reality to create a new fictional text, and in the fictional text itself there is a reality being shown.

Judith Pernin: You have talked about your interest in music, and I have the feeling that in 24 City you don't use music in the same way as in your previous films. Could you say something about this?
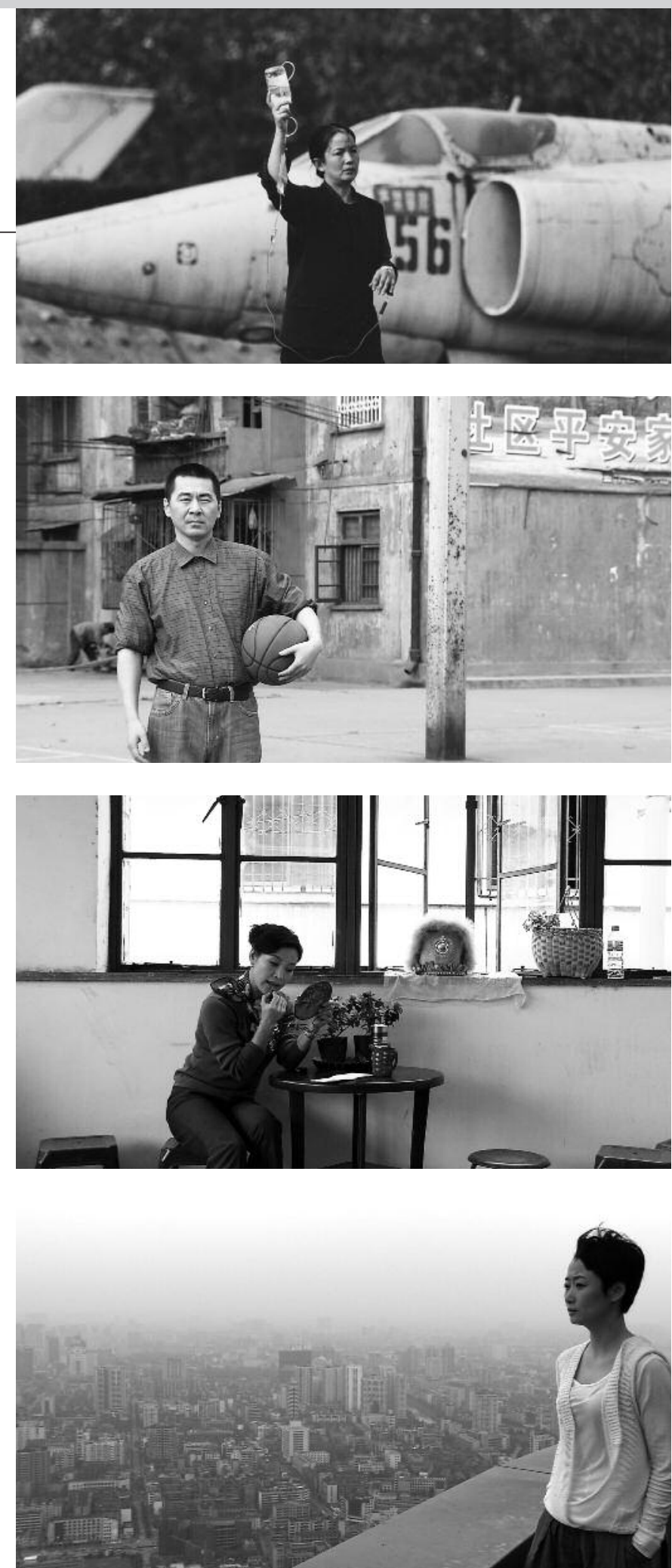

JZK: I used to mainly use live sound: if a character was watching television in the film, then you would hear the sound of the television. In 24 City I used mainly subjective music. I worked with two composers: Yoshihiro Hanno and Lim Giong. Hanno took charge of the first half, with its strict rules and orderly feeling; at the end of the film, which is more individual and freer, I used Lim Giong's electronic music. These two types of music actually comment on the narrative of the film, which is not only a record of the trans- 
formation from a planned to a market economy, but even more of what this change meant for individuals, the change from collectivism to individualism. The people who used to work in the factory really considered themselves as screws in the machinery, whereas after the 1980s, when a new selfawareness developed, and still today, people began to pay attention to individual freedom: this was a momentous change. When I shot this film, I also underwent a change in my own understanding. When I began to work on the film, I entered it with a very critical mindset, because all the material I had read underscored the pressure and constraints exercised by the system on individuals. But when I really went to interview them, I realised that when they had chosen to work in the system, it was often a very idealistic choice, a very pure and humane choice, because they wanted to change China, to remake the human being, to bring individuals happiness. History is very complex, and you can't judge it simplistically, so in all my films I hope to build a complex image of Chinese reality, Chinese society.
For example, I very much like long takes; I like their distinct discursive appeal: people's natural attitude, in a perfect space and time, and the sense of time they convey. But in addition to all these aesthetic reasons, I think long takes have a distinctly democratic quality: they don't cut off characters, but observe them; they contain a latent respect for characters. So I hope the entire film can refrain from imposing any concepts on the audience; I hope each member of the audience can impose their own subjectivity and invest their own experience in the film, make their own judgment. All these techniques are in fact a form of rebellion against the previous revolutionary film models, because I believe that we need to elaborate more common norms by making films. Of course this also has to do with my own evolution, because the process of making films is also a process of destroying the limitations of our own education and opening up to principles of greater freedom and equality.

\section{- Transcribed and translated by Sebastian Veg}

